\title{
The Relationships between Online Game Player Biogenetic Traits, Playing Time, and the Genre of the Game Being Played
}

\author{
Jun Won Kim ${ }^{1}$ \\ Doug Hyun Han ${ }^{1 凶}$ \\ Doo Byung Park' \\ Kyung Joon Min' \\ Churl Na ${ }^{1}$ \\ Su Kyung Won ${ }^{2}$ \\ Ga Na Park ${ }^{3}$ \\ 'Department of Psychiatry, \\ School of Medicine, \\ Chung Ang University, Seoul, \\ ${ }^{2}$ WITH Dr. Kim, Psychiatric Clinic, Seoul, \\ ${ }^{3}$ Department of Special Education, \\ Graduate School, Dankook University, \\ Jukjeon, Korea
}

Objective Psychobiological traits may be associated with excessive Internet use. This study assessed the relationships between biogenetic traits, the amount of time spent in online game playing, and the genre of the online game being played.

Methods Five hundred sixty five students who enjoyed one of the four types of games included in this study were recruited. The types of games examined included role playing games (RPG), real-time strategy games (RTS), first person shooting games (FPS), and sports games. Behavioral patterns of game play, academic performance, and player biogenetic characteristics were assessed.

Results The amount of time that the participants spent playing online games was significantly greater on weekends than on weekdays. On weekends, the types of games with the largest numbers of participants who played games for more than three hours were ranked as follows: RPG and FPS, RTS, and sports games. The Young's Internet Addiction Scale (YIAS)score for the RPG group was the highest among the groups of the four types of game players. The time that participants spent playing games on weekdays was negatively associated with academic performance, especially for the RPG and FPS groups. Compared with the other groups, the RPG and RTS groups had higher novelty seeking (NS) scores and self-directedness (SD) scores, respectively. Additionally, the sports game group had higher reward dependency scores than the other groups.

Conclusion These results suggest that RPGs may have specific factors that are attractive to latent game addicts with higher NS scores. Additionally, excessive playing of online games is related to impaired academic performance.

Psychiatry Investig 2010;7:17-23

Key Words Online game, Academic performance, Temperament and character inventory.

Received: September 9, 2009 Revised: January 27, 2010 Accepted: February 8, 2010

Available online: February 8, 2010

\section{Introduction}

More than $70 \%$ of the population of Korea, or about 35 million people, have access to the Internet. ${ }^{1}$ In particular, Korean teenagers are leading the rapid increase in the number of Korean Internet users. ${ }^{2}$ Among adolescents, the most frequent use of the Internet is playing of online games. ${ }^{3-5}$ During the abrupt expansion of the Internet user population, playing excessive video games which has beaen referred to as a computer game addiction and thought to be associated with academic, developmental, and behavioral problems among adolescents. ${ }^{3,6}$ Grüsser and colleagues ${ }^{6}$ reported that $11.9 \%$ of the 840 adolescents met the diagnostic criteria of addiction based on their behavioral patterns when playing games.

\section{$\mathrm{TCl}$ and internet addiction research}

The Temperament and Character Inventory (TCI) developed by Cloninger ${ }^{7}$ is widely used to assess psychobiological traits of human behavior. In previous studies using the TCI, it was re- 
ported that higher reward dependence (RD) is associated with impaired function of the dopamine D2 receptor and slower dopamine degradation among students engaging in excessive Internet use. $^{8}$

Participants engaging in excessive Internet use also displayed higher levels of harm avoidance (HA) behaviors. ${ }^{9}$ Additionally, Ko and colleagues ${ }^{10}$ reported that high novelty seeking (NS), high HA, and low RD are predictive of Internet addiction among adolescents. Moreover, Cho and colleagues ${ }^{11}$ proposed that psychobiological traits should be considered one of the etiologies of excessive Internet use among adolescents and adults. Lee and colleagues ${ }^{12}$ reported that personality profiles affect the severity of Internet game addiction, alcohol use, and smoking behavior among Korean adolescents. In particular, it was found that players who enjoy role playing games (RPG) tend to have higher Internet addiction scores than players who enjoy other genres of games.

However, the majority of previous studies ${ }^{11,12}$ have recruited individuals with Internet game addictions without considering the different characters of the online game genres which these individuals played. In this study, it is hypothesized that biogenetic traits among Internet game players will influence both the type of the game genre chosen and the amount of time spent playing Internet games.

\section{Classification of online games}

Previously, online games have been classified into eight categories, including arcade, real-time strategy, role playing, adventure, sports, action, first person shooting, and board games. ${ }^{13,14}$ Among these types of games, RPG (41.57\%), first person shooting games (FPS, $21.7 \%$ ), real-time strategy (RTS, $15.09 \%)$, and sports $(6.02 \%)$ games are the most popular in Korea. ${ }^{15}$ The objective of RPGs is to develop a character in the game by solving specific missions. In these types of games, each character has his or her own role in the game, and each user takes part in the game in order to communicate and cooperate in making progress and advancing the storyline. ${ }^{16,17}$ FPS games are shooting games which can be further categorized as arcadestyle games. While playing FPS games, the player must shoot weapons from the first-person point of view in order to defeat the enemy. ${ }^{17,18}$ This type of game requires quick thinking and decision-making. The third type of game is the RTS. In this type of game the purpose is to defeat one's opponent using one's own strategy. ${ }^{17,19}$ The most famous games representing this genre are Starcraft ${ }^{\circledR}$ and Warcraft $^{\circledR}$, in which the players take on specific roles and make advances on the basis of their own strategic decisions. Finally, the sports games simulate real-life sports, such as football, baseball, basketball and so forth. ${ }^{17} \mathrm{Am}-$ ong these type of game, the winners and losers are decided within a relatively short period of time, and these types of games require intense competition, quick decision making, and cognitive flexibility. ${ }^{17,20}$

\section{Hypothesis}

The aim of this study was to assess the relationships among biogenetic traits, excessive game playing, and the genre of the online games chosen. We hypothesized that psychobiological traits are associated with excessive Internet game play.

\section{Methods}

\section{Subjects}

Six hundred and sixty nine students who enjoy playing online games from two middle schools in Seoul, South Korea were recruited. For the screening of psychiatric problems, the Symptom Checklist-90-Revision (SCL-90-R), ${ }^{21}$ the Beck Anxiety Inventory (BAI), ${ }^{22}$ and the Children's Depression Inventory $(\mathrm{CDI})^{23}$ were administered to all participants. For the purpose of our research, we used the Junior TCI Korean version, consisting of 108 true and false items. ${ }^{24}$ Participants with histories of psychiatric illnesses, such as attention deficit and hyperactivity disorder, major depressive disorder, anxiety disorders, and head traumas, were excluded. Young's Internet Addiction Scale (YIAS) ${ }^{25}$ and questionnaires including questions about the amount of time they spend playing Internet games, the participant's preferred game type, and demographic characteristics were also used. For the classification of game genre, all of the games listed by the participants were sorted into the four genres described above. ${ }^{15}$ For the assessment of academic performance, school stress was self-rated using a seven-point Likert scale, and the academic quality of the participant was rated by each student's school teacher using a fivepoint Likert scale. The study protocol was approved by the Ethics Committee of Chung-Ang Yong San Hospital.

Among the 773 students, 669 students have participated in this study. And the 565 participants who usually played one of the popular four game types were selected (male/female $=452$ / 113); RPG [n=191 (139/52), 28.6\%], RTS [n=138 (131/7), $20.6 \%$, FPS [n=128 (120/8), 19.1\%], and sports [n=108 (62/ $46), 16.1 \%]$. Students who usually played other genre games $[n=104(67 / 43), 15.5 \%]$ were not included in analysis due to research goal. One hundred four students were excluded due to a lifetime history of neuropsychiatric illness, behavioral problems, an unstable mood or anxiety status assessed with the SCL-90-R, BAI, or CDI, and incomplete answers in responding to the questionnaires. Among the excluded 104 students, seven participants had a history of major depression. Eight participants had a history of attention deficit and hyperactivity disorder. The scores of the CDI in 23 students were over 19. Fifty seven students did not completely answer the questionnaires.

The distribution of academic performance among the 565 participants is described below; 1 grade (upper 20\%) included 167 participants (29.6\% of the sample), 2 grade included 168 participants ( $29.7 \%$ of the sample), 3 grade included 135 participants $(23.9 \%$ of the sample), 4 grade included 40 partici- 
pants ( $7.1 \%$ of the sample), and 5 grade (lower $20 \%$ ) included 55 participants $(9.7 \%$ of the sample). Three hundred twenty four students $(57.3 \%)$ had played their favorite game for more than six months. Ninety three (16.5\%), 82 (14.5), and 66 (11.7\%) had played their favorite game for less than one month, 1-3 months, and 3-6 months, respectively.

There was a significant difference in the amount of time spent playing online games between weekdays and weekends $\left(\chi^{2}=75.4, p<0.001\right)$. The number of students who played online games over three hours per day was greater on weekends. On weekdays, 310 students (54.9\%) played online games for one to three hours per day. One hundred seventy six (31.2\%), $49(8.7 \%)$, and $30(5.3 \%)$ students played less than one hour, three to six hours, and more than six hours per day, respective- ly. On weekends, 269 students (47.6\%) played online games for one to three hours per day. One hundred thirty four $(23.7 \%)$, $91(16.1 \%)$, and $71(12.6 \%)$ students played for three to six hours, less than one hour, and more than six hours per day, respectively.

\section{Data analysis}

Demographic and clinical variables involving continuous and categorical data were compared using linear regression analyses, analysis of variance (ANOVA), and chi-square tests. Temperament, character, and severity of game dependency among the four game groups were compared using an ANOVA. In each of the four game groups, the correlations among school stress, grades, playing time on weekdays and weekends, YIAS

Table 1. Demographic characteristics between four games

\begin{tabular}{|c|c|c|c|c|c|c|}
\hline & RPG & RTS & FPS & Sports & $\chi^{2 / f}$ & $\mathrm{p}$ \\
\hline Sex (man/woman) & $139 / 52$ & $131 / 7$ & $120 / 8$ & $62 / 46$ & 75.0 & $<0.001^{\mathrm{a} *}$ \\
\hline Age (years) & $13.9 \pm 0.8$ & $14.0 \pm 0.9$ & $13.8 \pm 0.8$ & $13.9 \pm 0.8$ & 4.6 & $0.004^{\mathrm{b} *}$ \\
\hline$<13(\%)$ & $68(35.6)$ & $56(40.6)$ & $60(46.9)$ & $63(58.3)$ & & \\
\hline $14(\%)$ & $69(36.1)$ & $29(21.0)$ & $34(26.6)$ & $23(21.3)$ & 24.9 & $<0.001$ \\
\hline $15(\%)$ & $54(28.3)$ & $53(38.4)$ & $34(26.6)$ & $22(20.4)$ & & \\
\hline Education (years) & $7.9 \pm 0.8$ & $8.0 \pm 0.9$ & $7.8 \pm 0.8$ & $7.6 \pm 0.8$ & 4.8 & $0.002^{\mathrm{c} *}$ \\
\hline 7 & $68(35.6)$ & $56(40.6)$ & $61(47.7)$ & $65(60.2)$ & & \\
\hline 8 & $69(36.1)$ & $28(20.3)$ & $32(25.0)$ & $20(18.5)$ & 28.8 & $<0.001^{\mathrm{c} *}$ \\
\hline 9 & $54(28.3)$ & $54(39.1)$ & $35(27.3)$ & $23(21.3)$ & & \\
\hline YIAS & $43.6 \pm 14.1$ & $38.8 \pm 12.4$ & $41.6 \pm 13.1$ & $39.0 \pm 12.8$ & 4.6 & $0.003^{\mathrm{d} *}$ \\
\hline BAI & $8.3 \pm 9.9$ & $6.9 \pm 8.4$ & $7.0 \pm 8.2$ & $7.0 \pm 9.0$ & 0.9 & 0.5 \\
\hline $\mathrm{CDI}$ & $13.1 \pm 7.0$ & $12.3 \pm 6.9$ & $13.0 \pm 7.0$ & $12.8 \pm 6.8$ & 0.4 & 0.7 \\
\hline Economy state & & & & & 1.7 & 0.6 \\
\hline High $(\%)$ & $39(20.4)$ & $27(19.6)$ & $26(20.3)$ & $22(20.4)$ & & \\
\hline Middle (\%) & $138(72.3)$ & $102(73.9)$ & $94(73.4)$ & $82(75.9)$ & & \\
\hline Low $(\%)$ & $14(7.3)$ & $9(6.5)$ & $8(6.3)$ & $4(3.7)$ & & \\
\hline School stress & $4.2 \pm 1.6$ & $4.0 \pm 1.6$ & $4.2 \pm 1.7$ & $4.2 \pm 1.8$ & 0.7 & 0.6 \\
\hline Grade of study & & & & & 0.7 & 0.4 \\
\hline Upper $20 \%$ & $52(27.2)$ & $44(31.9)$ & $35(27.3)$ & $36(33.3)$ & & \\
\hline $20<\mathrm{G}<40$ & $55(28.8)$ & $46(33.3)$ & $36(28.1)$ & $31(28.7)$ & & \\
\hline $40<\mathrm{G}<60$ & $45(23.6)$ & $32(23.2)$ & $32(25.0)$ & $26(24.1)$ & & \\
\hline $60<\mathrm{G}<80$ & $16(8.4)$ & $8(5.8)$ & $13(10.2)$ & $3(2.8)$ & & \\
\hline Less $80 \%$ & $23(12.0)$ & $8(5.8)$ & $12(9.4)$ & $12(11.1)$ & & \\
\hline G_Duration (month), n (\%) & & & & & 1.7 & 0.2 \\
\hline $\mathrm{D}<1$ & $39(20.4)$ & $15(10.9)$ & $14(10.9)$ & $25(23.1)$ & & \\
\hline $1<\mathrm{D}<3$ & $20(10.5)$ & $19(13.8)$ & $20(15.6)$ & $23(21.1)$ & & \\
\hline $3<\mathrm{D}<6$ & $24(12.6)$ & $15(10.9)$ & $18(14.1)$ & $9(8.3)$ & & \\
\hline $6<\mathrm{D}$ & $108(56.5)$ & $89(64.5)$ & $76(59.4)$ & $51(47.2)$ & & \\
\hline
\end{tabular}

$<13$ : below 13 years old, Post hoc test (Bonferroni test, ${ }^{*} \mathrm{p}<0.01$ ). a: girls $>$ boys, Sports $>$ RPG $>$ RTS=FPS, b: RPG $=$ RTS $=$ FPS $>$ sports, c: RPG=RTS=FPS $>$ Sports, d: RPG $>$ RTS=FPS=Sports. BAI: Beck Anxiety Inventory, CDI: Children's Depression Inventory, FPS: first person shooting game, G_duration: playing game duration, RPG: role playing game, RTS: real-time strategy, YIAS: Young's Internet Addiction Scale 
(dependant variables), and game genre (independent variable) were tested with linear regression analyses. Statistical significances were defined at an alpha level of 0.05 at two tailed significance. Considering multiple comparisons in TCI analysis, the significance was defined as 0.007 (0.05/7). Statistica 6.0 (StatSoft Inc., Tulsa, OK, USA) was used for all analyses.

\section{Results}

\section{Demographic characteristics of players}

There was an unequal sex distribution in the full sample $(\mathrm{M}=452, \mathrm{~F}=113)$, and there was a significant difference between four game groups $\left(\chi^{2}=75.03, \mathrm{p}<0.01\right)$. The mean of
YIAS was $41.1 \pm 13.4$ (20-93). The YIAS score in the RPG group was the highest among four game groups $(\mathrm{F}=4.6, \mathrm{p}=$ $0.003)$. YIAS scores were correlated positively with both time spent in game play on weekdays $(r=0.24, p<0.001)$ and weekends $(\mathrm{r}=0.32, \mathrm{p}<0.001)$. In a model considering school stress, genre of game, time spent playing games on weekdays and weekends, and YIAS scores, it was determined that spending time in game play on weekdays was associated uniquely with academic performance as assessed by student grades $(\mathrm{t}=4.1$, $\mathrm{p}<0.001$ ). In particular, the games which were most highly associated with the grades were the RPG $(\mathrm{t}=2.9, \mathrm{p}=0.004)$ and the FPS games $(\mathrm{t}=3.8, \mathrm{p}<0.001)$. The age of the participant $(\mathrm{F}=$ $4.6, p=0.004)$ and number of years of education of the partici-

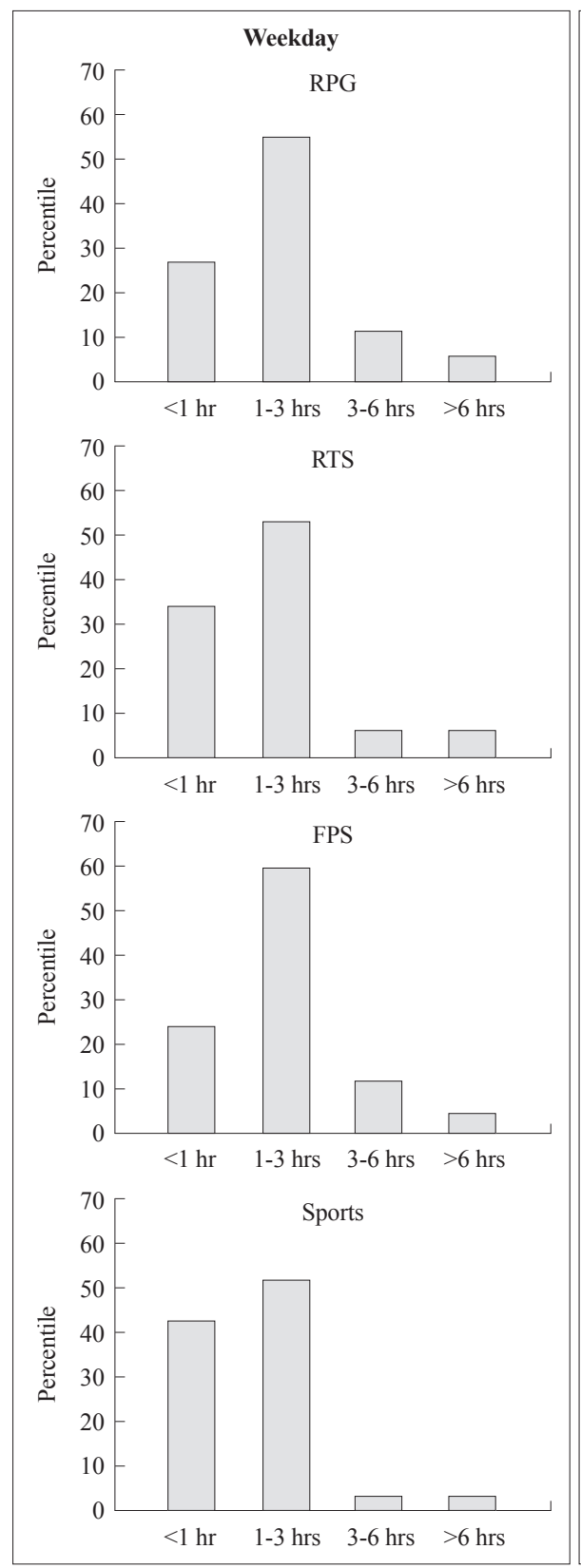

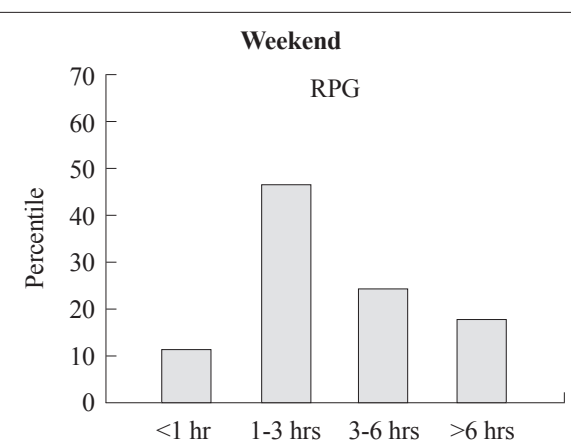
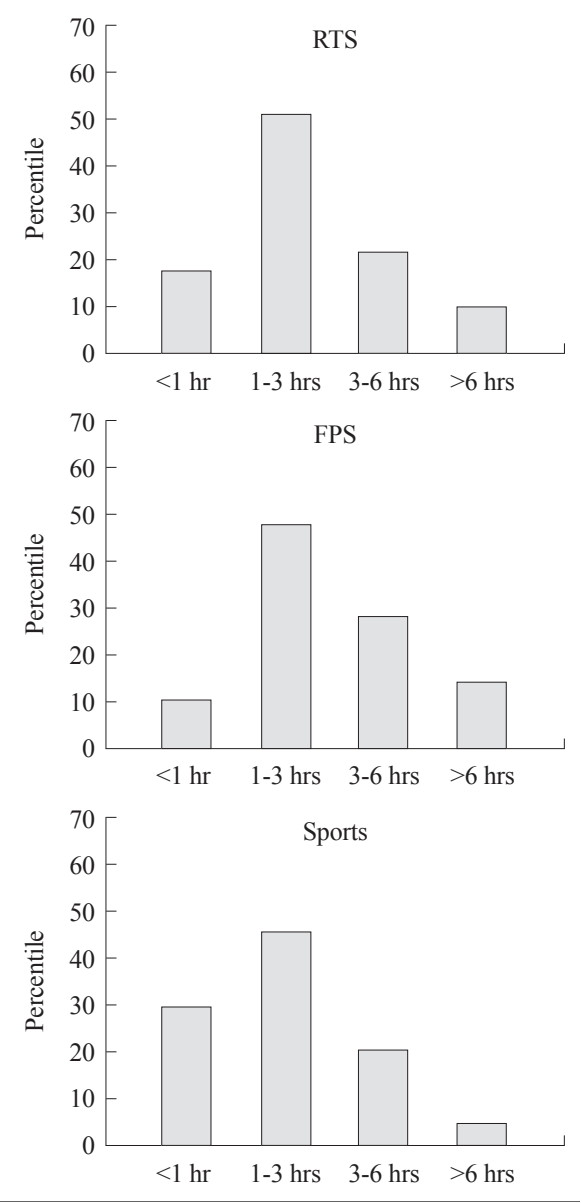

Figure 1. Playing time of game on weekday and weekend (\%). $\chi^{2}$-test, hour/day, weekday: $\chi^{2}=6.8, p<0.001$, weekend: $\chi^{2}=$ 12.2, $\mathrm{p}<0.001$. post hoc test: $3-6$ hours playing game on weekday: $\mathrm{RPG}=\mathrm{RTS}=$ FPS $>$ Sports on weekday, over 3 hour playing game on weekend: $R P G=F P S>$ RTS>Sports. RPG: role playing game, RTS: real time strategy, FPS: first person shooting game. 
pant $(\mathrm{f}=4.8, \mathrm{p}=0.002)$ were significantly lower in sports game than the other types of games. The number of 13 years olds $\left(\chi^{2}=24.9, \mathrm{p}<0.001\right)$ and middle school students in the seventh grade $\left(\chi^{2}=28.8, p<0.001\right)$ in the sports game group were significantly lower than among the other games. Girls were more likely to enjoy RPG and sports games than the other types of games $\left(\chi^{2}=75.0, \mathrm{p}<0.001\right)$. However, there were no significant differences in socio-economic status, grade stress levels, and school stress levels among the four groups (Table 1).

Each game genre group had significant increases in time spent playing on weekends compared to weekdays (RPG, RTS, FPS, and sports, $\chi^{2}=31.2, \mathrm{p}<0.001, \chi^{2}=14.4, \mathrm{p}<0.001, \chi^{2}=$ $22.1, \mathrm{p}<0.001$, and $\chi^{2}=10.6, \mathrm{p}=0.001$, respectively)(Figure 1). On weekdays, fewer students played sports game at a level of three to six hours when compared to other types of games $\left(\chi^{2}=3.9, p=0.048\right)$. On weekends, the number of students who played games for more than three hours was ranked in order as RPG and FPS, RTS, and sports $\left(\chi^{2}=4.6, \mathrm{p}=0.03\right)$ (Figure 1).

\section{Relationships between temperament, characteristics, and choice of game}

NS scores were associated with the amount of time playing games on weekdays $(\mathrm{B}=0.03, \mathrm{t}=2.8, \mathrm{p}=0.006)$ and weekends $(\mathrm{B}=0.04, \mathrm{t}=3.5, \mathrm{p}=0.001)$. Additionally, NS scores were also correlated positively with YIAS scores $(r=0.34, p<0.001)$.

The RPG group had higher NS scores, compared to other genre groups $(\mathrm{F}=7.6, \mathrm{p}<0.001)$. The RTS group had higher self-directedness (SD) scores than the other groups $(\mathrm{F}=6.9$, $\mathrm{p}<0.001)$. Additionally, the sports game group showed higher RD scores than the other groups $(\mathrm{F}=4.8, \mathrm{p}=0.003)$ (Table 2$)$.

In the RPG group, NS scores were associated with playing time on weekends $(\mathrm{B}=0.05, \mathrm{t}=2.6, \mathrm{p}=0.01)$ and positively correlated with YIAS scores $(r=0.37, p<0.001)$. In the FPS and sports groups, there were no significant correlations between playing time on weekdays, weekends, and YIAS scores.

\section{Discussion}

The current study revealed that there are differences in sex ratios, severity of Internet gaming addictions, school performances, and time spent on weekdays and weekends among the four game genres. Additionally, it appears that the choice of genre of Internet video game players is associated with biogenetic traits, as assessed by the TCI. The biogenetic traits assessed also were associated with the characteristics of Internet video game play patterns on weekdays or weekends.

Although it is not surprising that there is a negative correlation between playing time of games and academic achievement, it is interesting that academic performance was associated not with school stress, but game playing game on weekdays, especially among the RPG and FPS groups. Moreover, students who favored RPGs had high NS scores, which were correlated with playing time on weekends and with YIAS scores. In accordance with these results, a study of adolescent smoking reported that early smoking was associated with high NS scores and poorer academic performance. ${ }^{26}$

In chemical addiction research, NS has been shown to be associated with cravings for substances. ${ }^{27}$ High NS also has been reported in game addictions research. ${ }^{11}$ Moreover, RPG gamers had higher Internet addiction scores, when compared to simulation, role playing, web board, community, action, adventure, shooting, and sports games. ${ }^{28}$ RPGs have been designed to involve meeting new gamers and cooperating or fighting with others. ${ }^{16,17}$ Therefore, the RPG group was expected to show more characteristics of higher RD or higher cooperativeness. However, this group had higher NS scores. Interestingly, previous studies have shown the relationship among dopamine, NS and addiction. As such, we consider the relation between RPG and NS to be in line with the characteristics of NS. That is, new stimulation leads to reactions strengthening behaviors. ${ }^{7,29} \mathrm{NS}$ as a personality trait has been reported to be associated with medial frontal activity. ${ }^{30}$ A role for craving in the medial frontal cortex has also been suggested in the subjects treated with methylphenidate. ${ }^{31}$ In studies of increased risk of drug addiction among adolescent, imaging studies have suggested that the craving for drugs and dependency may be due to immaturities of the prefrontal cortex during the adolescent period..$^{32,33}$ In particular, Gogtay and colleagues ${ }^{33}$

Table 2. Comparisons of temperament and characteristics between four games

\begin{tabular}{lrrrrrr}
\hline & \multicolumn{1}{c}{ RPG } & \multicolumn{1}{c}{ RTS } & \multicolumn{1}{c}{ FPS } & \multicolumn{1}{c}{ Sports } & $\mathrm{f}$ & \multicolumn{1}{c}{$\mathrm{p}$} \\
\hline NS & $8.5 \pm 3.2$ & $7.1 \pm 2.9$ & $7.4 \pm 2.9$ & $7.2 \pm 3.1$ & 7.6 & $<0.001^{\mathrm{a} *}$ \\
HA & $10.1 \pm 4.9$ & $9.6 \pm 4.6$ & $10.0 \pm 4.3$ & $10.2 \pm 5.5$ & 0.5 & 0.7 \\
RD & $8.4 \pm 2.7$ & $8.9 \pm 2.6$ & $8.7 \pm 2.6$ & $9.6 \pm 2.8$ & 4.8 & $0.003^{\mathrm{b} *}$ \\
SD & $10.3 \pm 3.9$ & $12.0 \pm 3.3$ & $10.4 \pm 3.7$ & $10.6 \pm 3.7$ & 6.9 & $<0.001^{\mathrm{c*}}$ \\
C & $13.3 \pm 3.8$ & $13.8 \pm 3.6$ & $13.5 \pm 3.8$ & $14.2 \pm 3.7$ & 1.5 & 0.2 \\
ST1 & $1.9 \pm 1.6$ & $1.9 \pm 1.6$ & $2.0 \pm 1.5$ & $1.9 \pm 1.4$ & 0.1 & $<1$ \\
ST2_3 & $2.9 \pm 1.5$ & $2.8 \pm 1.5$ & $2.8 \pm 1.5$ & $3.0 \pm 1.6$ & 0.2 & 0.9 \\
\hline
\end{tabular}

Post hoc test: a: RPG $>$ RTS=FPS=Sports, b: Sport $>$ RPG=RTS=FPS, c: RTS $>$ RPS=FPS=Sports. ${ }^{*}$ p $<0.007$. C: consistency, FPS: first person shooting game, HA: harm avoidance, NS: novelty seeking, RD: reward dependence, RPG: role playing game, RTS: real-time strategy, SD: self-directedness, ST1: creative self-forgetfulness, ST2: transpersonal identification, ST3: spiritual acceptance 
suggested that prefrontal maturation continues throughout the early twenties. Cunningham and colleagues ${ }^{32}$ declared that unstable cognitive modulation of emotion in adolescent addicts may be associated with under developed prefrontal cortex maturation. Therefore, current results indirectly support the relationship between immature prefrontal cortex development which is associated with high NS and addictionrelated traits. Taken together, we suggest that students who enjoy RPG may be more vulnerable to Internet game addictions than players who play other genres of games as they had higher NS and YIAS scores compared to students who played the other types of games. Additionally, the results of this study showed that playing excessive RPG online games is associated with reduced academic performance.

RTS games, which reflect the player's strategic prowess, ${ }^{17,19}$ were associated with SD in the current study. Previously, low SD has been shown to be associated with remitted depression. ${ }^{34}$ In our previous report,$^{10}$ we suggested that students engaging in excessive Internet use tend to have depressive tendencies. Considering previous reports and our current findings, we also cautiously suggest that RTS may be used as a self medication among students engaging in excessive Internet use.

Sports game users spent lesser time on weekday and weekend than other game users. In addition, Sports game had high $\mathrm{RD}$ scores. The characteristics of Sports game contains clear winner and loser in short period of time, and gains recognition from others ${ }^{17,19}$ which maybe induce strong relation with RD tendency. RD score represents the sensitiveness of a person which is highly stimulated by social rewards. ${ }^{7,29}$

\section{Limitations}

There are several limitations to the current study. First, because we have investigated only the relationship between biogenetic traits and the choice of game genre, other factors which may be related to Internet use were not considered. Specifically, Park and colleagues $(2008)^{35}$ have suggested that family attitudes, such as parenting, communication, cohesion, and violence exposure are important factors in Internet addiction. Ko and colleagues ${ }^{10}$ have reported that attention deficit disorder may be associated with Internet addiction. Second, we simplified various games into four genres. Third, our study only included the adolescent version of Junior TCI. Finally, few female students were recruited in this study. Future large studies are needed to consider factors, such as family, attention, and environment that we excluded in this paper.

\section{Clinical implications}

Former studies have shown that Internet game addicts have characteristics that are different from those of substance abusers. ${ }^{36}$ As the etiological factors related to these disorders differ, we believe that therapies targeting these disorders should be different as well. As the research shows, the biogenetic traits of teenagers differed according to the genres of games they favor. It may be that the preference of game genre and the nature of the addiction can function as contributing factors, and the prevention and treatment for game addiction may require a consideration of each of the characteristics, as well as the nature of the individual.

\section{REFERENCES}

1. National Internet Development Agency of Korea. Available at: http:// isis.nida.or.kr. Accessed September 8, 2009.

2. Lyoo IK, Ha JH, Yang EJ, Kim YM, Chang CG, Woo JI. Psychopathology of internet addiction: perspective of impulsivity and compulsivity. Kor J Psychopathol 2000;9:16-26.

3. Ha JH, Yoo HJ, Cho IH, Chin B, Shin D, Kim JH. Psychiatric comorbidity assessed in Korean children and adolescents who screen positive for Internet addiction. J Clin Psychiatry 2006;67:821-826.

4. Siomos KE, Dafouli ED, Braimiotis DA, Mouzas OD, Angelopoulos NV. Internet addiction among Greek adolescent students. Cyberpsychol Behav 2008;11:653-657.

5. Korea Agency for Digital Opportunity and Promotion. Available at: http://www.kado.or.kr. Accessed September 8, 2009.

6. Grüsser SM, Thalemann R, Griffiths MD. Excessive computer game playing: evidence for addiction and aggression? Cyberpsychol Behav 2007;10:290-292.

7. Cloninger CR, Svrakic DM, Przybeck TR. A psychobiological model of temperament and character. Arch Gen Psychiatry 1993;50:975990 .

8. Han DH, Lee YS, Yang KC, Kim EY, Lyoo IK, Renshaw PF. Dopamine genes and reward dependence in adolescents with excessive internet video game play. J Addict Med 2007;1:133-138.

9. Lee YS, Han DH, Yang KC, Daniels MA, Na C, Kee BS, et al. Depression like characteristics of 5HTTLPR polymorphism and temperament in excessive internet users. J Affect Disord 2008;109:165-169.

10. Ko CH, Yen JY, Chen CC, Chen SH, Wu K, Yen CF. Tridimensional personality of adolescents with internet addiction and substance use experience. Can J Psychiatry 2006;51:887-894.

11. Cho SC, Kim JW, Kim BN, Lee JH, Kim EH. Biogenetic temperament and character profiles and attention deficit hyperactivity disorder symptoms in Korean adolescents with problematic Internet use. Cyberpsychol Behav 2008;11:735-737.

12. Lee MS, Ko YH, Song HS, Kwon KH, Lee HS, Nam M, et al. Characteristics of internet use in relation to game genre in Korean adolescents. Cyberpsychol Behav 2007;10:278-285.

13. Elverdam C, Aarseth E. Game classification and game design: construction through critical analysis. Games and Culture 2007;2:3-22.

14. Korean Entertainment System Industry Association (KESA). The present and future of online game in Korea. Available at: http://www. game.or.kr. Accessed September 8, 2009.

15. Game Report. Available at: http://gamereport.netimo.net. Accessed September 8, 2009.

16. Appleman R, Goldsworthy R. The juncture of games \& instructional design: Can fun be learning? Paper presented at annual meeting of the Association of Educational Communications and Technology. Houston: TX; 1999.

17. Ministry of Culture, Sports and Tourism. Available at: http://www. mcst.go.kr. Accessed September 8, 2009.

18. Massimino MJ, Sheridan TB. Teleoperator performance with varying force and visual feedback. Hum Factors 1994;36:145-157.

19. Aha DW, Molineaux M, Ponsen M. Learning to win: case-based plan selection in a real-time strategy game. Lecture Notes in Computer Science 2005;3620:5-20.

20. Claypool M, Claypool K. Latency and player actions in online games. 
Communications of the ACM 2006;49:40-45.

21. Kim KI, Kim JH, Won HT. Korean manual of Symptom Checklist-90Revision. Seoul: Jung Ang Juk Sung Publisher; 1984.

22. Fydrich T, Dowdall D, Chambless DL. Reliability and validity of the beck anxiety inventory. J Anxiety Dis 1992;6:55-61.

23. Kovacs M. The Children's depression, inventory (CDI). Psychopharmacol Bull 1985;21:995-998.

24. Ha JH, Yoo HJ, Cho IH, Lyoo IK, Shin JK, Kim JH, et al. The reliability and validity of the Korean version of junior temperament and character inventory (JTCI). Kor J Psychopathol 2005;14:3-10.

25 . Young, KS, Rodgers RC. The relationship between depression and Internet addiction. Cyberpsychol Behav 1998;1:25-28.

26. Audrain-McGovern J, Rodriguez D, Tercyak KP, Cuevas J, Rodgers K, Patterson F. Identifying and characterizing adolescent smoking trajectories. Cancer Epidemiol Biomarkers Prev 2004;13:2023-2034.

27. Martinotti G, Cloninger CR, Janiri L. Temperament and character inventory dimensions and anhedonia in detoxified substance-dependent subjects. Am J Drug Alcohol Abuse 2008;34:177-183.

28. Lee MS, Ko YH, Song HS, Kwon KH, Lee HS, Nam M, et al. Characteristics of internet use in relation to game genre in Korean adolescents. Cyberpsychol Behav 2007;10:278-285.

29. Cloninger CR. A systematic method for clinical description and classification of personality variants. A proposal. Arch Gen Psychiatry 1987; 44:573-588.
30. Bermpohl F, Pascual-Leone A, Amedi A, Merabet LB, Fregni F, Wrase J, et al. Novelty seeking modulates medial prefrontal activity during the anticipation of emotional stimuli. Psychiatry Res 2008;164:81-85.

31. Volkow ND, Wang GJ, Fowler JS, Hitzemann R, Angrist B, Gatley $\mathrm{SJ}$, et al. Association of methylphenidate-induced craving with changes in right striato-orbitofrontal metabolism in cocaine abusers: implications in addiction. Am J Psychiatry 1999;156:19-26.

32. Cunningham MG, Bhattacharyya S, Benes FM. Amygdalo-cortical sprouting continues into early adulthood: implications for the development of normal and abnormal function during adolescence. J Comp Neurol 2002;453:116-130.

33. Gogtay N, Giedd JN, Lusk L, Hayashi KM, Greenstein D, Vaituzis AC, et al. Dynamic mapping of human cortical development during childhood through early adulthood. Proc Natl Acad Sci U S A 2004;101: 8174-8179.

34. Hansenne M, Bianchi J. Emotional intelligence and personality in major depression: trait versus state effects. Psychiatry Res 2009;166: 63-68.

35. Park SK, Kim JY, Cho CB. Prevalence of internet addiction and correlations with family factors among South Korean adolescents. Adolescence 2008;43:895-909.

36. Kim EJ, Namkoong K, Ku T, Kim SJ. The relationship between online game addiction and aggression, self-control and narcissistic personality traits. Eur Psychiatry 2008;23:212-218. 